\title{
FLUORIDE, TEETH AND THE ANALYST
}

A MEETING on "Fluoride, Toeth and the Analyst", held by tho Society for Analytical Chemistry at the Wellcomo Building, Euston Road, London, N.W.1, on November 7, under the chairmanship of Dr. A. J. Amos, provided an opportunity for discussion betweon chemists of widely different interests and specializations.

Dr. H. J. Cluley (General Electric Co., Ltd., Hirst Research Centre, Wembley, Middlesex) spoke on "The Determination of Fluoride in Inorganic Materials by Pyrohydrolysis". Fluorine, he said, interfored with tho determination of a number of elements and was itself frequently difficult to determine. One particular difficulty arose from the lack of selectivity of the methods available for the determination of fluoride, so that for fluoride in inorganic materials a preliminary separation of the fluoride from most other elements was almost invariably necessary. The most common method of separation was that of Willard and Winter in which fluoride was distilled as fluosilicic acid; however, this was subject to serious interference from aluminium, boron and gelatinous silica and hence was of little practical value to the silicate analyst.

Against this background, an alternative means of separation was required and 'pyrohydrolysis' offered a method of rapidly separating fluorine from a variety of inorganic materials. This technique involved heating the sample, usually mixed with a suitable 'accelerator', in a current of steam or moist oxygen; the fluorine was evolved as hydrogen fluoride which could be condensed and determined by titration.

The method originated in the atomic energy field where it was observed that the fluorides of uranium and of aluminium, bismuth, magnesium, vanadium, zine, zirconium and rare earths wero rapidly hydrolysed on heating in a current of stoam. Other fluorides such as those of calcium, strontium and barium were more reluctant to part with their fluorine but the addition of an accelerator, for example, $\mathrm{U}_{8} \mathrm{O}_{8}$ or alumina, facilitated thoir hydrolysis. More recently, tungstic oxide and vanadium pentoxide had been used as accelerators.

Originally, a platinum reactor tube had been used for the pyrohydrolysis. It had now been shown practicable to use a silica reactor tube in conjunction with a glass water-cooled condenser, since the concentration of hydrofluoric acid vapour was always low and the time of contact with the apparatus was short. Typically, pyrohydrolysis was continued for $15-30 \mathrm{~min}$ at approximatoly $1,000^{\circ} \mathrm{C}$, with a fast flow of steam to give $3-5 \mathrm{ml}$. of condensate per $\min$.

Where conventional methods require lengthy separations, for examplo, the determination of fluorine in silicate materials, the rapidity afforded by the pyrohydrolysis technique is of particular advantage. Dr. Cluley described how the technique had permitted the rapid determination of 5 per cent of fluorine in opal glass, giving results of high precision. He had also used pyrohydrolysis to determine $0 \cdot 02-0 \cdot 10$ per cent fluorine in very small dentine samples which were supplied by Dr. G. N. Jenkins (who was to speak later) and which originated from 'low' and 'high' fluorine areas.

Dr.J. Longwell (deputy government chemist, Laboratory of the Government Chemist, Clement's Inn Passage, Strand, London, W.C.2) dealt with the fluoridation of water supplies from the analyst's point of view. Not enough was known about the vast amount of work that had been devoted to this subject during recent years in the United States and in Great Britain; it had been the subject of detailed study without parallel in prevontive medicino. He recalled how the condition of childron's teeth had improved during the Second World War when sugar and sweets were rationed and how their condition had since worsened, and showed colour slides to illustrate tho gravity of the problem.

Survoys of children's teoth in the United States had shown how the numbers of docayed, missing and filled teeth wore much lower or nil in the areas where naturally occurring fluoride was present and the practice of fluoridation of water supplies at a level of 1 p.p.m. had since been adopted. The improvement in dental health that had been observed after fluoridation for some fifteen years in the United States was described and illustrated.

In 1952, a group from Great Britain went to North America to study the fluoridation of water and, on returning, recommended that fluoride be added to the water supplies of several selected communities before the general adoption of fluoridation. Studies were first carried out on the availability of fluoride in food and drink and on the amounts that would be ingested with and without fluoridation of the water. Fluoridation was started in Kilmarnock, Watford and Anglesey in 1955-56 and a report had just been published by the Ministry of Health et al. giving the results obtained after five years of fluoridation (soe Nature, 195, 760; 1962).

The methods used to add fluoride in a steady and con. trolled concentration to the water supplies in Britain were outlined and emphasis was laid on the care taken to ensure control-which was two-fold. First, the amount of fluoride actually added was recorded as was the volume of water pumped and from these figures the concentration of fluoride ion in the water was calculated. Chemical determinations at the water plant, using a $\mathrm{r}$ isual colorimetric zirconium-alizarin lake mothod were confirmed at the Laboratory of the Government Chemist, using distillation from perchloric acid to remove any interfering ion, followed by colorimetric determination. Moro than 20,000 samples examined in the five years gave an average of 0.94 p.p.m. fluorine, with a standard deviatic $n$ of about 0.1 p.p.m. fluorine. The improvement in the deciduous teeth of children in the three study areas, as a result of fluoridation, was illustrated; the reduction of about 60 per cent in the incidence of caries in 3- and 4-year-old children was similar to that observed in the United States, and even more interesting was the increase in the percentage of children with complotely sound teoth, from 32 to 60 per cent at 3 years and from 22 to 42 per cent at 4 years.

In time, teeth of older age groups would be improved and teeth of older children and adults in natural fluoride areas were examples of what could and should be achioved by fluoridation. Dr. Longwell ended his talk by showing coloured photographs of teeth of two children, typical of many, living in a natural fluoride area.

Dr. G. N. Jenkins (Reader in Oral Physiology, Medical School, King's College, University of Durham, Newcastlo upon Tyno) concerned himself with the role of analysis in investigating the mode of action of fluoride in tooth decay. Fluorine was present in teeth as a result of an ion exchange reaction with the hydroxyapatite of the calcified tissues, and hence in aroas with a water of high fluorine content the fluorapatite of the teoth was also high. Topical application of high concentrations of fluoride led to other reactions-doublo decomposition leading to the deposition or adsorption of calcium and magnesium fluorido, and hence the mochanisms involved by such mothods, for example, in toothpastos, wore certainly very different and incompletely understood.

Studies of the distribution of fluorine in the tooth showed a very definite pattern, the concentration being much higher in the outer onamel layers than deoper in 
the tissues of the tooth. Nevertheless, the concentrations even in these deeper enamel layers were higher in teeth from high than from low fluoride areas. The lesser solubility of fluorapatite compared with hydroxyapatite suggested a possible mode of action in reducing the incidence of caries, and detailed investigations of solubility were deseribed in which the outer surfaces of teeth from high and low fluoride aroas were compared. The large variation tooth-to-tooth made valid comparison very difficult and the slightly lower solubility found for teeth from a 1 p.p.m. fluorine area, as compared with a zero fluorino area, was not statistically significant. At 2 p.p.m., however, a statistically significant lowering by 21 per cent in the solubility was recorded. The choice of analytical method was of importance in the solubility determina. tions; in some conditions different results were obtained, according to whether phosphorus or calcium was measurod, and workers in the United States had investigated the problem by gravimotric determinations of solubility on powders ground from successive layers of the teeth. By this method, too, the teeth with highest fluoride con. tont were also the most soluble. Experiments with radioactive fluoride revealed that the tooth took up fluorido more readily in the nieghbourhood of a caries blemish, and it had been found that the differences between the fluoride of enamel from areas of high and low intake of fluoride were greater when carious enamol was studied.

Other properties of the fluoride ion were discussed that might be related to its action in reducing dental decay.
Since it favoured the precipitation of calcium phosphate from unstable and metastable solutions, such as saliva, it might intermittently reverse the removal of calcium salts in, and thus slow the development of, a dental cavity. The role of fluoride as an enzyme poison might also be related to its decay-inhibiting properties. Attempts were therefore being made to study the fluoride content of the 'dental plaque' (the muco-bacterial film on the tooth surface) -an analytical problem of some magnitude when it is realized that only about $10 \mathrm{mg}$ of plaque can be obtained from one person. It had been shown to be significantly higher in subjects from 'high fluoride' areas. Partial rolease of the bound fluoride in plaque might occur if the $p \mathrm{H}$ bocamo sufficiently acid, as it probsbly did after eating carbohydrate. It had been found with saliva that the addition of fluoride at a concentration similar to that of plaque was effective not moroly in preventing the production of acid from carbohydrate by salivary bacteria but could actually bring about an increase in $p \mathrm{H}$.

That fluoridation of public water supplies was a subject of great topical interest was evident from the lively discussion that followed each paper. The analyst, it was clear, had an important part to play by devoloping and applying sensitive methods that were essential not only to ensure its proper regulation and control but also to provide the basic tools for the study of the fundamental mechanism by which fluoride exerted its beneficial offoct.

S. A. PrICE

\section{GROWTH AND NUTRITION OF A WHOLE PLANT}

A NYONE interested in the growth of the whole plant should find a recently published memoir interesting, for they will find it a refreshing revision course dealing with some theories of contemporary botany in a more stimulating way than is usually found in text-books*. Prepared by Prof. F. C. Steward and three colleagues it contains, in Parts 2-5, information about the anatomy, growth and development of mint grown with a wide range of nutrient-levels (some of which led to deficiency symptoms) and different light and temperature conditions. Parts 4-6 have details of many chemical analyses, involving chromatographical techniques, carried out on roots, stems and leaves of plants grown under a wide range of environmental conditions. The final section is a synthesis of the earlier parts.

Although the morphology of the plant does make it readily acceptable to sampling procedures, the decline in popularity of mint as an experimental plant (discussed in Part 1) must largely be due to the fact that large numbers of plants are usually needed for experiments associated with analysis of growth. Raising plants from seods is more satisfactory from many points of viow than from cuttings. There are no troubles in keeping stock plants

* Growth, Nutrition and Metabolism of Mentha piperita L. Parts 1-7. Memoir 379, Cornell University Agricultural Experimental Station, Ithaca, New York. August 1962, 144 pages. alive, no labour-demanding jobs such as preparing cuttings, and less variation in initial size of plant. The rapid growth rate of mint is obviously valuable; but the fact that it produces much lateral growth and a large number of small leaves is a disadvantage when compared with plants producing a few large leaves from a main axis. The unbranched plant, particularly one the form of which is similar under a wide range of environmental conditions, will, unlike mint, have similar efficiencies of light utilization in, for example, long- and short-day conditions. Would the results of the many chemical analyses that are presented in Parts 4-6 of the memoir have been similar if a plant with a single main axis had been used ?

These first seven parts contain a great deal of informa tion about effects of length of day, night temperature and mineral nutrition on some cell constituents; some information in future parts on effects of amount of incident radiation, spectral composition of light and perhaps other environmental variables would obviously give a more complete picture. Finally, most botanists would agree that the chemical analyses which were done on mature tissues should be extended to the growing regions, not only to apical meristems, but also to all organs throughout periods of cell division, expansion and differentiation if a better understanding of organization of growth is to be obtained.
P. Newton

\section{THE CENTRAL FOOD TECHNOLOGICAL RESEARCH INSTITUTE, MYSORE}

$\mathrm{T}$ is not uncommon to find that scholarly academic work is undertaken in underdeveloped countries while practical problems of vital interest to the economy of the State are neglected. Sometimes technological laboratories equipped with foreign capital do not function satisfactorily because of lack of suitable personnel. Some of these problems are no doubt due to the type of training given to students sent to Europe and elsewhere, but others to lack of proper incentives presented by the Governments concerned. None of these criticisms can, however, bo applied to the Central Food Technological Research Institute at Mysore, which, under its director, Dr. V. Subrahmanyan, is rapidly building a reputation in SouthEast Asia. The report of its work during 1960-61 covers 